Ha-Joon afirma que (p. 25), "[...]Tanto quanto me é dado saber, este livro é o único que oferece informações em um espectro tão amplo de instituições, passando por um grande número de países". No último capítulo, intitulado "Lições para o presente", o autor tenta responder os seus questionamentos iniciais, dando algumas sugestões para os países em desenvolvimento.

Após a análise do desenvolvimento econômico sob um prisma histórico, Ha-Joon conclui que se os países desenvolvidos tivessem mesmo adotado as políticas que recomendam aos países em desenvolvimento, não seriam o que são hoje. Muitos deles, ao longo de sua trajetória de desenvolvimento, recorreram a políticas comerciais e industriais protecionistas, atualmente consideradas políticas "ruins". Além disso, no século XIX e início do século XX, antes de se tornarem países desenvolvidos, possuíam poucas das instituições que agora recomendam aos países em desenvolvimento. Em outras palavras, os países desenvolvidos, pregando políticas ortodoxas, estariam hoje "chutando a escada" para que os países em desenvolvimento não consigam seguir os mesmos caminhos trilhados por eles para se desenvolver.

O ponto alto do livro são os dados históricos que questionam determinados mitos em relação aos países desenvolvidos. Por exemplo, na tabela 2.1 (pág. 36), fica claro que, de 1820 até 1931, os EUA e alguns outros países hoje desenvolvidos adotaram políticas altamente protecionistas para defender a sua indústria nascente, mas eles alegam que fizeram o contrário: que liberalizaram seus mercados. Em um trecho do livro (pág. 66), que analisa as políticas de ICT adotadas pela Alemanha, menciona-se a utilização de espio- nagem industrial patrocinada pelo Estado e a cooptação de trabalhadores da Inglaterra, práticas que seriam consideradas "ruins" nos dias de hoje. Em uma outra parte do livro (págs. 12736), Ha-Joon demonstra que, nos países desenvolvidos, a democracia, durante muito tempo, não foi muito democrática, porque excluía pessoas por renda, sexo, cor... Existia também compra de votos, fraude eleitoral e corrupção. Segundo o autor, os países em desenvolvimento, nas fases iniciais da democracia, não tiveram tantos problemas como os países desenvolvidos.

O livro é de leitura fácil, com abundância de dados históricos não só de países tradicionalmente analisados como EUA, Alemanha, França, Grã-Bretanha e Japão, mas também de países menores, como a Bélgica, Suíça, Holanda, etc. Apresenta, assim como em outros livros do mesmo autor, uma visão crítica em relação ao papel do Estado no desenvolvimento econômico e em relação às políticas recomendadas aos países em desenvolvimento pelos órgãos de fomento internacional como o Banco Mundial e o Fundo Monetário Internacional.

É um trabalho original, recomendado para leitura a economistas e pessoas com diversas áreas de formação, inclusive a formuladores de políticas públicas. Contém inúmeras referências bibliográficas e estimula a repensar as estratégias de desenvolvimento econômico que vêm sendo adotadas pelos países pobres e em desenvolvimento.

Carmen Augusta Varela

Professora da Escola de Administração

de Empresas de São Paulo

da Fundação Getúlio Vargas

\title{
Freakonomics: o lado oculto e inesperado de tudo que nos afeta
}

Steven D. Levitt e Stephen J. Dubner Rio de Janeiro: Elsevier, 2005.

Em um tempo em que estudantes e profissionais queixam-se do elevado grau técnico das discussões acadêmicas em Economia, surge um livro que busca, de maneira simples e irreverente, revelar as diversas possibilidades de aplicação da teoria econômica. É principalmente por esta razão que o lançamento do livro Freakonomics: o lado oculto e inesperado de tudo que nos afe- ta, de autoria de Steven D. Levitt e Stephen J. Dubner deve ser saudado.

Recentemente, ocorreram esforços semelhantes ao dos autores. Por exemplo, o livro Sexo, drogas e E conomia, de Diane Coyle (São Paulo: Futura, 2003), equivale a uma tentativa de apresentar uma introdução didática a temas pouco convencionais vistos sob o prisma da Ciência 
Econômica. Apesar desse texto possuir um certo apelo em certos trechos, pelas sugestões de aplicações criativas que fornece, não equivale a uma obra com o mesmo grau de articulação que Freakonomics.

À primeira vista, pode parecer que as situações abordadas por Levitt e Dubner beirem o trivial e tenham pouca importância em termos práticos. Entretanto, esta visão revela-se como enganosa a partir da leitura das primeiras páginas do livro. Além de seguirem uma linha agora tradicional em Economia - a de aplicar princípios econômicos às mais variadas situações da vida cotidiana, tradição esta iniciada por economistas como Gary Becker - os autores preocupam-se em confrontar explicações baseadas na chamada "sabedoria convencional”. Este último termo é usado ao longo do texto para denotar idéias simples, convenientes e confortadoras, geralmente aceitas pela maior parte da sociedade, mas que não são necessariamente verdadeiras. Na verdade, essa definição do termo já fora empregada décadas antes por John Kenneth Galbraith, no seu conhecido livro A sociedade afluente (São Paulo: Pioneira, 1987 [edição original de 1958]. De certa forma, o fato dos autores basearem-se nos ensinamentos de autores com visões de mundo tão distintas como Becker e Galbraith apenas demonstra seu forte ecletismo intelectual.

Mas também se engana quem achar que a variedade inerente aos autores fica limitada a suas fontes. Tanto os tópicos abordados ao longo do livro quanto as formas de abordagem empregadas variam enormemente. Freakonomics é, por si só, uma exposição didática de algumas das mais interessantes contribuições em termos de Economia aplicada feitas nos últimos anos. O foco principal do livro são as contribuições do próprio Levitt, recipiente da Medalha Clark em 2003, um prestigioso prêmio acadêmico dado a economistas norte-americanos abaixo dos quarenta anos de idade. Assim como outros economistas laureados com essa premiação, Levitt tem como uma de suas principais características a criatividade, enxergando aplicações surpreendentemente simples de princípios econômicos aos mais variados fenômenos cotidianos (Dubner, Stephen J. The economist of odd questions: inside the astoningshingly curious mind of Steven D. L evitt. Documento disponível na Interntet: http://www.stephenjdubner.com/journalism/economist.html. e Magalhães, Matheus A. de. Criatividade em Economia: um guia idiossincrático, mimeo, fev. 2004). Ao longo da exposição relacionando algumas de suas contribuições, o leitor vai tendo contato gradual com contribuições adicionais de outros autores, que vão desde a análise econômica da criminalidade até explicações relacionadas ao baixo rendimento de crianças negras na escola, por exemplo.

Os autores iniciam o primeiro capítulo do livro tratando de um tema bastante atual: as origens da corrupção. Para tanto, exploram o papel fundamental dos incentivos e como esses podem, muitas vezes, acabar induzindo à trapaça nas mais diversas ocasiões. Os autores expõem distintas situações onde a corrupção pode estar presente. Por exemplo, devido a políticas educacionais mais exigentes, um professor do ensino fundamental pode decidir modificar as notas de seus alunos em testes padronizados, de modo a ter um bom desempenho perante seus superiores. Em um trabalho em co-autoria, Levitt criou um programa de computador capaz de detectar professores "trapaceiros". No caso, a partir das notas de turmas com desempenhos variados, os autores conseguem detectar os trapaceiros a partir de notas significativamente mais altas do que aquelas reportadas para turmas onde os alunos apresentavam um desempenho escolar abaixo da média. Na prática, o resultado desse empreendimento foi a demissão de alguns professores identificados como trapaceiros. Do mesmo modo, também foi possível identificar os melhores professores a partir do desempenho de seus alunos em testes padronizados. Em outra ocasião, os autores demonstram a existência de corrupção no sumô japonês a partir da análise de lutas "em impasse" (em que a derrota de um dos lutadores levaria a sua desclassificação no torneio). Os resultados obtidos demonstram que lutadores nessa situação tendem a sair vitoriosos em um número significativamente superior de lutas àquele que seria previsível em média, o que pode representar um sinal de conluio entre lutadores. Embora ainda recente, esse tipo de abordagem representa um esforço pioneiro de fornecer alguma evidência empírica referente ao fenômeno da corrupção, uma vez que a maior parte da literatura econômica relacionada ao tema nos últimos anos possui um caráter eminentemente teórico.

Problemas decorrentes de assimetria de informação são o tema do segundo capítulo. Nele, os autores demonstram a importância da informação, tanto na economia como na sociedade como um todo. O capítulo inicia com um relato breve e parcial da história da Klu Klux Klan, uma antiga instituição racista norte-americana. $\mathrm{O}$ re- 
lato é baseado na visão de Stetson Kennedy, inimigo declarado da Klan, com os autores ressaltando como a divulgação de informações relacionadas a essa instituição acabou sendo o fator responsável, em certo grau, por sua derrocada. Em seguida, é ressaltado o papel fundamental da Internet para diminuir a assimetria de informação existente em diversos mercados, como o mercado de seguros de vida e o de caixões, por exemplo. As explicações mais interessantes relacionadas a esses fenômenos estão no final do capítulo, no entanto. Nesse trecho, os autores atentam para a possibilidade de diversos especialistas aproveitarem-se do conhecimento privilegiado que possuem sobre os mercados onde atuam. Um exemplo nesse sentido seriam os corretores de imóveis. Sendo um grupo de profissionais que detêm informações privilegiadas em relação aos bens que ofertam, os corretores podem recomendar a seus clientes que vendam suas casas na primeira oportunidade que têm, muitas vezes deixando de receber valores superiores caso esperassem mais um tempo no mercado antes de tomar a decisão de vender os respectivos imóveis. Adicionalmente, os autores reportam resultados de um estudo onde corretores tendem a manter as próprias casas no mercado por um prazo superior ao de seus clientes, uma evidência adicional de abuso de informação privilegiada, bem como de corrupção.

No terceiro capítulo do livro, os autores partem da seguinte questão: por que a maioria dos traficantes de drogas, apesar de estarem envolvidos com uma atividade altamente rentável, ainda apresentam um baixo padrão de vida? A resposta a essa questão está relacionada com a própria organização econômica dessa atividade. Segundo os autores, o tráfico pode ser visto como um empreendimento que, como uma grande empresa, busca maximizar seus lucros. À semelhança de uma grande empresa, o tráfico apresenta uma hierarquia em forma de pirâmide, onde existe uma grande quantidade de traficantes pequenos ("soldados") que atua nas ruas sob a orientação de gerentes ("líderes"). Apenas os traficantes que possuem cargos próximos ao topo dessa pirâmide ganham bons salários. A maioria dos "soldados" ganha valores irrisórios ou, em muitos casos, nem sequer recebem salários, trabalhando de graça e esperando uma oportunidade de serem efetivados pelas gangues em que atuam. Uma das razões apontadas pelos autores para o alto número de jovens envolvidos nessa atividade é o seu status: apesar de ser extrema- mente difícil subir nessa hierarquia, aqueles que conseguem fazê-lo acabam obtendo altas recompensas. O problema é que, ao longo do tempo, poucos conseguirão chegar lá (o mesmo é válido para carreiras artísticas e esportivas, por exemplo). O final do capítulo explora a ascensão do crack nos Estados Unidos e suas conseqüências em termos de criminalidade. Inexplicavelmente, pouco tempo depois do boom do crack nesse país, as taxas de criminalidade começaram a cair, a despeito das previsões contrárias feitas por diversos especialistas na época.

O quarto capítulo do livro talvez seja o mais controverso. Nele, os autores buscam fornecer possíveis explicações para a queda acentuada dos índices de criminalidade nos Estados Unidos na década de 90. Ao longo do capítulo, são analisadas algumas das principais explicações citadas na mídia para a queda da criminalidade, como a existência de uma economia mais forte, o aumento do número de policiais, a implementação de estratégias policiais inovadoras e mudanças no mercado de drogas, por exemplo. Essas explicações, baseadas fortemente na sabedoria convencional, são examinadas individualmente pelos autores. Sua conclusão demonstra que a maior parte dessas explicações não poderiam ter efetivamente contribuído para a queda observada da criminalidade. Adicionalmente, atentam para a contribuição de uma causa oculta, nunca antes citada. A controvérsia do capítulo relaciona-se ao fato dos autores ressaltarem a importância da legalização do aborto cerca de vinte anos antes, bem como seu impacto sobre as taxas de criminalidade. O raciocínio por trás desse argumento é o seguinte: filhos indesejados teriam maior probabilidade de se tornarem criminosos devido às condições precárias de vida a que estariam sujeitos durante sua criação. Em relação a esse tema, a substância da questão, apesar de extremamente controversa, não é tão fundamental quanto pode parecer à primeira vista. $\mathrm{O}$ aspecto interessante, no caso, é como os autores trazem um fator totalmente novo à discussão pré-existente, rompendo com a sabedoria convencional. Na verdade, esta já é uma tradição mais antiga no meio acadêmico norte-americano, especialmente na Universidade de Chicago, onde Levitt leciona desde 1997. Se o aspecto levantado pelos autores é relevante ou não, somente a pesquisa futura poderá dizer. Mas esse trecho do livro é extremamente interessante por demonstrar a necessidade de desafio constante das convenções 
estabelecidas, uma atitude acadêmica extremamente saudável.

O quinto e o sexto capítulos do livro apresentam um tema unificado: a importância dos pais na criação dos filhos. O quinto capítulo trata basicamente de questões relacionadas ao desempenho escolar infantil, com uma ênfase no caso norteamericano, onde ocorrem diferenças significativas entre brancos e negros em termos de notas. Uma possível explicação para essas diferenças equivaleria ao fato de ocorrerem pressões internas a grupos de negros que desestimulassem certos comportamentos "socialmente desejáveis", como o bom desempenho escolar, por exemplo. Jovens negros que fossem contra essas pressões, poderiam ser identificados como "agindo feito brancos", podendo sofrer punições físicas e morais por isso. No sexto capítulo, são expostos os resultados de uma pesquisa recente de Levitt, relacionada à importância dos nomes sobre as carreiras profissionais dos indivíduos. No caso norte-americano, será que nomes nitidamente negros influenciam a empregabilidade dos indivíduos detentores desses nomes? Citando estudos atuariais, os autores concluem que sim. Pessoas com nomes nitidamente negros sofrem uma punição econômica por isso, deixando de receber o mesmo número de ofertas de emprego que pessoas com nomes nitidamente brancos recebem. Um outro resultado interessante é o seguinte: existe uma forte relação entre a escolha de certos nomes de bebês e o status socioeconômico dos pais. No final desse capítulo, os autores chegam a arriscar a elaboração de uma lista de nomes mais populares de meninos e meninas para o ano de 2015.

Ao longo do livro, os autores desenvolvem uma abordagem didática e acessível, chegando inclusive a explicar termos técnicos de Economia e Econometria sem sequer mencionar suas denominações comuns (conforme é o caso do problema de endogeneidade e das técnicas econométricas de variáveis instrumentais e efeitos fixos, por exemplo). Entretanto, não se limitam a enaltecer apenas técnicas quantitativas ao longo do livro (embora façam isso em certos trechos). Procuram, em algumas partes, demonstrar a importância de fatos históricos relacionados aos fenômenos em estudo. Esse é o caso, por exemplo, quando tratam do aumento do tráfico de crack nos Estados Unidos, assim como das conseqüências da proibição do aborto na Romênia ao longo da década de 60. O texto é fluido e instigante, o que talvez se deva ao fato de um dos autores (Dubner) ser jornalista.

O capítulo relacionado à forma de organização da Klu Klux Klan, por sua vez, apresenta trechos confusos e pouco articulados, em comparação ao restante do livro. Essa parte vale mais como curiosidade em termos de cultura geral do que em termos de evidência propriamente dita. Talvez isso ocorra devido ao fato de que o tema ainda estivesse sendo explorado por Levitt e um co-autor quando da preparação do livro.

Ao concluírem o livro, com o epílogo sobre "dois caminhos para Harvard", os autores citam trechos das trajetórias pessoais de Roland Fryer Jr., um jovem economista negro de Harvard e Ted Kaczynski, conhecido mundialmente como o "Unabomber", responsável por diversos atentados a bomba ao longo de duas décadas. À primeira vista, esse trecho apresenta uma conotação quase caricatural, uma vez que os indivíduos citados possuem características específicas que acabaram destacando-os em termos das trajetórias seguidas. O fato de um jovem negro, criado em condições precárias (conforme foi o caso de Fryer), ter chegado a uma prestigiosa instituição de ensino diz tão pouco sobre as possibilidades dos negros norte-americanos quanto o fato de um jovem branco e bem-nascido (Kaczynski) ter se tornado um ermitão anti-social diz sobre a formação de terroristas. Talvez fosse exatamente essa a intenção dos autores ao finalizar o livro com o trecho citado: demonstrar que toda regra tem sua exceção e que as características individuais, bem como o ambiente social, desempenham um papel importante ao longo da vida, não devendo ser subestimadas quando do estudo de temas sociais. Entretanto, essa conjectura não chega a ser explicitada ao longo do texto. De modo geral, pode-se concluir, a partir de uma primeira leitura de Freakonomics, que Levitt e Dubner prestam um enorme serviço à comunidade acadêmica ao escreverem um texto capaz de estimular alunos e professores com as (inúmeras) possibilidades da Economia moderna.

$M$ atheus A lbergaria de $M$ agalhães Mestre em Teoria Econômica pelo IPE-USP 